\title{
ВЛИЯНИЕ КУЛЬТУРЫ СУПРУЖЕСКИХ ОТНОШЕНИЙ НА ВОСПИТАНИЕ И УСПЕВАЕМОСТЬ МЛАДШИХ ШКОЛЬНИКОВ
}

\author{
А. Д. Плотников \\ (Московский гуманитарный университет), \\ И. Г. Савельева \\ (Школа-гимназия № 4 г. Лыткарино Московской области)
}

Аннотация: В статье рассматриваются проблемы культуры супружеских отношений, супружеского насилия и их влияние на воспитание и успеваемость младших школьников. Сделан анализ возникновения детских страхов и их последствий на жизнедеятельность детей. Сформулировань выводы о необходимости предотвращения домашнего насилия.

Статья подготовлена на основе доклада авторов на ХІІІ Международной научной конференции «Высшее образование для ХХІ века» (8-10 декабря 2016 г., г. Москва).

Ключевые слова: культура супружеских отношений; насилие; домашнее насилие; семейные отношения; супружеское насилие; успеваемость школьников; воспитательная функция; детские страхи

\section{THE CULTURE OF SPOUSAL RELATIONS AND ITS INFLUENCE ON THE UPBRINGING AND ACADEMIC PROGRESS OF PRIMARY SCHOOL PUPILS}

\author{
A. D. Plotnikov \\ (Moscow University for the Humanities) \\ I. G. Savelyeva \\ (Gymnasium No.4, Lytkarino, Moscow Oblast)
}

\begin{abstract}
The article examines the issues of spousal relations, family violence and the impact they have on the upbringing and academic progress of primary schoolers. We also analyze the genesis of children's fears and their role in the future lives of these children. We conclude that family violence must be prevented by all means.

The article is based in the paper delivered at the 13th international research conference "Higher education for the 21st century" (Moscow, December 8-10, 2016).

Keywords: culture of spousal relations; violence; family violence; relations within the family; academic progress at school; personality development (vospitanie); children's fears
\end{abstract}


Анализируя общие проблемы внутрисемейных отношений, мы попытались выяснить, как такие проблемы сказываются на степени реализации воспитательной функции в семье и успеваемости детей младшего школьного возраста. К сожалению, зависимость здесь оказалась прямой, причем ярко выраженной. И если в семье присутствуют к тому же элементы домашнего насилия, то как поведение детей в школе, так и их успеваемость проявляются в отчетливо выраженном негативном плане.

Акцентируем внимание на том, что в современных условиях культуру супружеских отношений в семьях не всегда можно охарактеризовать только с позитивной стороны. Достаточно напомнить о ежегодном росте насилия, которое присутствует во взаимоотношениях супругов, причем, наличие разных форм такого насилия приобретает сегодня угрожающие масштабы. И это все, бесспорно, крайне негативно отражается на качестве психологического состояния детей и восприятии ими учебного материала в рамках разных предметов школьных программ.

По причине недостаточной культуры в супружеских отношениях создается реальная угроза безопасности института семьи, реализации многообразных ее функций, в том числе функции воспитания. Проведенное нами исследование подтверждает, что современные семейные конфликты и насилие связаны с тяжелым экономическим, материальным положением семьи, безработицей и рядом других важных обстоятельств - таких, как характер личности, ее психофизиологические особенности, предпочтения, статус. В последнее десятилетие в российских семьях заметно снизилась материальная обеспеченность, что создало в них высокий уровень тревоги, напряженности, неуверенности, эмоциональной отчужденности. Последствия экономического и финансового кризиса, внутриполитические события усилили стрессовые факторы, влияющие на сознание и поведение взрослых членов семьи. Это прямым образом отразилось на снижении супружеской и родительской культуры, которые, конечно же, тесно взаимосвязаны.

Мы, как специалисты, смело утверждаем о наметившемся в этой связи росте в массовом сознании беспокойства и тревожности, усилении психологической напряженности, увеличении количества стрессов. Данные обстоятельства, без сомнения, могут сопровождаться депрессиями, повышенной тревожностью, что, в свою очередь, сказывается на проявлении агрессивных действий в отношениях членов семьи, прежде всего, супругов, создании более напряженной психологической атмосферы, которая выступает порой в качестве провоцирующей основы для разрешения конфликтных ситуаций, в том числе с применением супружеского насилия.

Дети, регулярно наблюдающие агрессивные действия между отцом и матерью, становятся жертвой такого рода отношений, фактически идеа- 
лизируют навязываемую им «культуру», жестокость и насилие. Родители не осознают, что ребенок при этом получает вместо необходимого ему воспитания «уроки» антигуманности и искаженного понимания семейных ценностей. Постепенно он начинает вести себя в социальной среде, в школьном коллективе не совсем адекватно, возводить насильственные задания действия в ранг собственной видения своей жизни и отношений с родителями, учителями сверстниками. Можно с уверенностью говорить о том, что низкая культура супружеских отношений, характеризующаяся, к тому же, проявлением насилия, наносит существенный вред здоровью ребенка, травмирует его психику, становится причиной формирования социально дезадаптивной личности, не способной к оптимальному и качественному выполнению заданий на уроках.

Изучение и анализ научной литературы показали, что тема супружеской культуры исследована недостаточно, остается важной в связи с необходимостью дальнейшего понимания учеными, а также самими родителями механизмов влияния системы отношений между отцом и матерью на формирование психики их детей. На наш взгляд, до сих пор нет универсального представления о том, что можно считать насилием и где грань, отделяющая его от ненасилия. По этой причине нет точного понятия насилия. Что касается определения «семейное насилие», то данный термин, по нашему мнению, также нуждается в уточнении. В научной литературе понятие семейного насилия можно чаще всего встретить в работах юридической и философской направленности. Термин «семейное насилие» как обобщенная категория с точки зрения психологии, к сожалению, не дается.

В литературе по вопросам психологии основными терминами в области проблематики насилия являются собирательные термины «abuse» (обида, ругань, оскорбления, жестокое обращение, пренебрежение, злоупотребление, эксплуатация, совращение) и «neglect» (пренебрежение, игнорирование, забывание, отсутствие заботы).

В данной работе семейное насилие рассматривается в более узком плане - с точки зрения влияния насильственных действий, существующих в отношениях супругов, на ребенка, на его поведение и успеваемость в школе. В этом смысле семейное насилие представляет:

- игнорирование его субъектных характеристик (свободы, достоинства, прав);

- разрушение отношения привязанности между взрослыми и ребенком, либо, напротив, фиксирование этого отношения;

- действия, приводящие к различным деформациям и нарушениям психического (поведенческого, интеллектуального, эмоционального, волевого, коммуникативного, личностного) развития. 
Низкий уровень супружеской культуры, а также применяемое в отношениях супругов насилие влияют на психологические особенности детей, значительно снижают их способности к самовыражению, доверие к людям, приводят к депрессиям, состоянию постоянного страха, тревожной неуверенности, нарушению способности к установлению эмоциональной близости. Запечатленное ребенком физическое насилие между родителями может приводить к садистским наклонностям, непроизвольно формируемым у их детей. К сожалению, многие родители не знают о том, что насилие, пережитое в детстве, может приводить к долгосрочным последствиям, зачастую влияющим на всю дальнейшую жизнь. Оно может способствовать формированию специфических семейных отношений, особых жизненных сценариев. Те, кто видит или участвует в сценах насилия, находясь в детском возрасте, обычно приобретают склонность к агрессии и проявлению насилия в школе, а также в своей семье по отношению к близким.

Следует подчеркнуть, что в разные периоды жизни реакция на семейное насилие может проявляться по-разному. Исходя из проведенного нами анализа, наиболее общими симптомами, в зависимости от возраста, являются:

- для детей до 3-х лет - страхи, спутанность чувств, в поведении отмечаются нарушения сна, потеря аппетита, агрессия, страх перед чужими людьми;

- для дошкольников - тревога, боязливость, спутанность чувств, чувство вины, стыда, отвращения, чувство беспомощности; в поведении отмечаются отстраненность, агрессия, сексуальные игры, мастурбация;

- для детей младшего школьного возраста - амбивалентные чувства (сложные противоречивые чувства, эмоции) по отношению к взрослым, сложности в определении семейных ролей, страх, чувство стыда, отвращения, недоверия к окружению; в поведении отмечаются отстраненность от людей, нарушения сна, аппетита, агрессивное поведение, ощущение «грязного тела», молчаливость либо неожиданная разговорчивость, сексуальные действия с другими.

Проведенные нами психологические исследования показали: низкая супружеская культура, насилие в отношениях родителей влияют на психологические и личностные особенности детей младшего школьного возраста, оказывают нежелательное антивоспитательное воздействие, снижение успеваемости, повышают уровень тревожности и агрессивности, увеличивают количество детских страхов.

Конечно, в качестве доказательной базы мы провели естественные эксперименты со специально отобранными 12-тью семьями (с недостаточно высокой культурой во взаимоотношениях между супругами и на- 
личием между ними насильственных действий). Основу изучения и анализа составили: длительное ознакомление с жизнью конкретных детей и родителей, активное участие в их делах, выполнение заданий в естественной, непринужденной обстановке (беседы, рисование, тесты). При этом естественные эксперименты были, как правило, формирующими (направленными на изучение психических явлений непосредственно в процессе активного формирования психических особенностей детей младшего школьного возраста, родители которых применяли насилие в собственных взаимоотношениях).

В целях более глубокого изучения вопросов влияния насилия между супругами на поведение их детей использовался метод наблюдения. В частности, нами проводилось непосредственное наблюдение за процессом отношений среди членов семей, включенное наблюдение (в определенной социальной ситуации). Наблюдение было систематическим и долговременным. Иногда использовался метод наблюдения за родителями и детьми в значимых ситуациях. Важными методами нашего исследования стали также беседы, анкетирование и тесты.

Долгое время под нашим наблюдением находились специально отобранные молодые супруги и, естественно, их дети. Причем во всех данных семьях имели место проявление грубого отношения между супругами в присутствии их детей, реальные факты насилия. Такого рода семьи и составили нашу экспериментальную группу. Нами была сформирована также контрольная группа из молодых семей (родители и их дети). Наблюдение велось в течение 4,5 лет.

Проведенные исследования дали интересные результаты, показав, что чем больше неблагоприятных психосоциальных факторов в семье, связанных с низкой культурой супружеских отношений, тем сильнее их негативное воздействие на развитие ребенка. При изучении семей с супружеским насилием установлено, что школьная дезадаптация во многом отражала нарушения в семейных взаимоотношениях. При этом в конфликтных семьях присутствовал особый психологический климат, который для ребенка всегда оказывался психогенным. Исполняя роль отвергнутого или арбитра, он вынужден был искать пути приспособления, которые нередко приводили к отклонению в поведении и нарушению

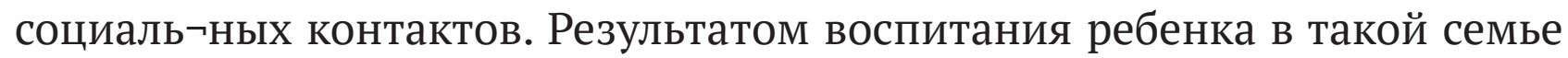
являлись, как правило, школьные проблемы, прежде всего в снижении успеваемости и ослаблении восприятия учебного материала. Такие выводы были сделаны нами на основе проведенного анализа рисунков и специальных тестов.

Из-за наличия в семьях низкой внутрисемейной культуры, дисгармоничных супружеских отношений ребенок становится фактическим субъектом данных отношений. Как могут быть вовлечены дети и подростки 
в супружеский конфликт? Какие формы такого вовлечения существуют непроизвольно? Во-первых, это вовлеченность ребенка в качестве объекта манипуляции. Такой прием используется, как правило, обидчиком для установления власти и контроля над взрослой жертвой. Во-вторых, опосредованная вовлеченность, при которой ребенок напрямую не является жертвой агрессивных действий - он лишь наблюдает за актами насилия. По оценкам специалистов, психологическая травма, получаемая «свидетелем» жестокого обращения, равна по силе и степени тому воздействию, которое имели дети - жертвы насилия.

Важно подчеркнуть: практически у всех детей, выросших в условиях наличия низкой супружеской культуры, агрессивных действий в отношениях супругов, имеются отклонения в сознании, травмы психологического характера. Именно поэтому супружеское «бескультурие», насилие являются существенным препятствием на пути нормального психического развития детей и подростков. А это обстоятельство непосредственно влияет на формирование их мировоззрения.

Следствием переживания, которое возникает в результате реальной или воображаемой опасности, является испытываемый ребенком страх. Дети, видящие в семье акты насилия или агрессивного поведения в отношениях родителей, бесспорно, волнуются за последствия таких действий. В этих случаях дети боятся потерять самых близких для них людей, переживают за создание неблагоприятной семейной атмосферы, которая во многом является фундаментом детской социализации. Серьезные конфликты родителей все чаще становятся для ребенка существенными раздражителями, приобретающими характер угрожающих воздействий. В этих случаях дети автоматически приобретают так называемый травмирующий опыт, который, как правило, характеризуется приобретением испугов, болезней, нарушением психики.

На наш взгляд, совершенно справедливо отмечает А. И. Захаров, что даже «разговоры при ребенке о смерти, несчастьях и болезнях, пожарах и убийствах помимо воли запечатлеваются в его психике. Все это дает основание говорить об условно-рефлекторном характере воспроизведения страха, даже если ребенок пугается (вздрагивает) при внезапном стуке или шуме, так как последний когда-то сопровождался неприятным переживанием. Подобное сочетание осталось в памяти в виде определенного эмоционального следа и теперь непроизвольно ассоциируется с любым внезапным звуковым воздействием» (Захаров, 2000: 448). Нам представляется, что эмоциональные впечатления, полученные от увиденных в раннем возрасте актов агрессии или насилия в отношениях родителей, во много раз сильнее. И это, увиденное или услышанное, влияет на психику детей и проявляется в их поведении особым образом. У таких детей 
фактически всегда присутствуют страхи, а это отпугивает, отвлекает от процесса восприятия учебного материала в школе.

В связи с тем, что дети, «соприкасающиеся» с агрессивным поведением своих родителей, характеризуются повышенными чувствами страха и тревоги, беспокойством, важно определить их симптомы. Ученые заостряют внимание на том, что в условиях проявления беспокойства ребенок или уже взрослый человек чаще теряются. Иногда они не могут подобрать нужные слова для ответа, говорят дрожащим голосом, замыкаются в себе, а порою просто замолкают.

Дети, ставшие невольными жертвами низкой супружеской культуры, насильственных действий между супругами, проявляют повышенное беспокойство. Таким детям свойственен хронический страх, который сказывается фактически на всех сферах их жизнедеятельности, способствует изменению поведения, существенному снижению успеваемости, задержке физического и умственного развития, речевого и моторного развития. В дальнейшем такие отклонения сказываются на здоровье, влияют на степень культуры и эффективность взаимодействия личности с социальной средой, на самореализацию человека и его карьерный рост.

Исходя из проведенного нами исследования, напрашивается вывод о том, что современное российское общество XXI века должно прилагать усилия к тому, чтобы в семьях присутствовала высокая культура отношений, где родители должны любить и уважать детей, а значит - не допускать фактов насилия в отношении как их, так и - самих супругов. Только в этом случае подрастающее поколение будет расти социально активным и творчески инициативным, создавать психически и физически здоровые семьи, а в дальнейшем быть примерными, педагогически грамотными и по-настоящему культурными родителями.

\section{СПИСОК ЛИТЕРАТУРЫ}

Захаров, А. И. (2000) Дневные и ночные страхи у детей. Серия «Психология ребенка». СПб.: «Издательство СОЮЗ».

Дата поступления: 15.11.2016 г.

Плотников Александр Дмитриевич - доктор исторических наук, профессор кафедры социологии Московского гуманитарного университета. Адрес: 111395, Россия, г. Москва, ул. Юности, д. 5. Тел.: +7 (916) 16679-38. Эл. адрес: rostsentrsem@yandex.ru

Савельева Ирина Геннадьевна - кандидат исторических наук, учитель обществознания Школы-гимназии № 4 г. Лыткарино Московской области. Адрес: 140083, Россия, Московская область, г. Лыткарино, квартал 3а, д. 4. Тел.: +7 (916) 920-88-62. Эл. адрес: saveleva.irina@mail.ru 
Plotnikov Aleksandr Dmitriyevich, Doctor of History, Professor, Department of Sociology, Moscow University for the Humanities. Postal address: 5 Yunosti St., 111395 Moscow, Russian Federation. Tel.: +7 (916) 16679-38. E-mail: rostsentrsem@yandex.ru

Savelyeva Irina Gennadievna, Candidate of History, Instructor in Social Studies, Gymnasium No.4, Lytkarino, Moscow Oblast. Postal address: 4 Block 3a, 140083 Lytkarino, Moscow Oblast. Tel.: +7 (916) 920-88-62.E-mail: saveleva. irina@mail.ru

\section{Для цитирования:}

Плотников А. Д., Савельева И. Г. Влияние культуры супружеских отношений на воспитание и успеваемость младших школьников [Электронный ресурс] // Научные труды Московского гуманитарного университета. 2016, № 6. URL: http://journals. mosgu.ru/trudy/article/view/379 (дата обращения: дд.мм.гг.). 